\title{
The road from mutation to next generation phenotyping: contribution of deep learning technology (Face2Gene) to diagnosis neurofibromatosis type 1
}

\author{
Muhsin Elmas®, Başak Göğüş®
}

Department of Medical Genetics, Afyonkarahisar Health Sciences University School of Medicine, Afyonkarahisar, Turkey

\begin{abstract}
Objectives: Genetics is one of the fastest growing medical fields in the last 10 years. While new analysis methods such as Next Generation Sequencing have been developed, the use of artificial intelligence like Face2Gene in this field has also been developed. The aim of this study is to evaluate the clinical, genetic and dysmorphic findings of Neurofibromatosis type 1 (NF1) patients, a disease of the RASopathy group. At the same time, another aim of this study is to evaluate and compare with other RASopathies diseases the success of Face2Gene application which is one of the NGP technologies, in this group of diseases.

Methods: This study is a retrospective archive scan. Fourteen patients from 3 different patient groups were selected for the study. Face2Gene analysis was performed for these groups. Detailed clinical, genetic and dysmorphic findings of NF1 patients were also examined.

Results: As a result of the genetic analysis of NF1 patients, one patient had novel mutation. The most detected mutation type is nonsense mutation (42.8\%). The most common finding in magnetic resonance imaging was hamartoma (29\%). Face2Gene suggested that NF1 in top-3 for 10 of 14 NF1 patients. Additionally, at the comparison of NF1 patients and non-NF1 RASopathies patients resulted as AUC was 0.749 and p value was 0.134 .
\end{abstract}

Conclusions: Considering the developments in technology in the last 10 years, it is thought that artificial intelligence applications such as Face2Gene will be used a lot in the routines of medical doctors in the next 10 years.

Keywords: Neurofibromatosis 1, cafe-au-lait spots, deep learning, artificial intelligence

$\mathrm{H}$ uman facial features are an important part of identity. The face was seen as an important part of the body. We recognize and define ourselves and others with facial features. However, in some cases the facial features are quite different from the "normal" facial features and these are very conspicuous. This situation has led to the rise of the "Dysmorphology" field. Dysmorphology refers as "birth defects and result from malformations, deformations, or disruptions, which generally have a significant and obvious effect on appearance" [1].

Dysmorphology has been curious and fantastic field since prehistoric times. The best examples of this are Tumaco-La Tolita Figurine in Colombia and

How to cite this article: Elmas $M$, Göğ̈̈s B. The road from mutation to next generation phenotyping: contribution of deep learning technology (Face2Gene) to diagnosis neurofibromatosis type 1. Eur Res J 2022:8(2):145-154. DOI: 10.18621/eurj.894631

Address for correspondence: Muhsin Elmas, MD., Assistant Professor, Afyonkarahisar Health Sciences University School of Medicine, Department of Medical Genetics, Afyonkarahisar,Turkey.E-mail: drmelmas@gmail.com,Tel (Mobil): +90 5554003484 
Ecuador showing the characteristic facial features of Down syndrome [2]. Additionally, in the literature, characters with dysmorphic features have gave inspire to the authors like Quasimodo in Victor Hugo's novel The Hunchback of Notre-Dame. In this novel, Quasimodo represents Neurofibromatosis type 1 (NF1) patient [3].

Presenting a disease-causing mutation to the phenotype is the greatest aid to clinical geneticists in diagnosis. 30-40\% genetic disorders have characteristic and distinct facial features. [4]. The importance of dysmorphology has increased in recent years with the development of new computer-based databanks (London Dysmorphology Database, Pictures of Standard Syndromes and Undiagnosed Malformations Database, Online Mendelian Inheritance in Man, etc.). With use these databases, the success of the prediagnosis is increasing with dysmorphic and physical examination findings [5]. One of these databases developed in recent years is the Face2Gene (FDNA Inc, Boston, USA) application. Face2Gene is one of the best examples of the next-generation phenotyping (NGP). This application is developed using computer vision and deep learning algorithms on the basis of Deep Gestalt technology [6]. This technology provides a community-driven phenotyping trained on thousands of patient images and used to analyze hundreds of syndromes. It also provides an analysis based on the clinical findings of the patients (Feature Match). In recent studies, the success rate of Face2Gene for the correct syndrome has been reported to be $86-91 \%$ in the top 10 recommendation disease list $[7,8]$. In this study, we considered both types of analysis and included an in-silico analysis in which photos of our research group were compared with 2 control groups.

One of the disease groups with dysmorphic facial features is RASopathies. The common features of this group of diseases are developmental delay, congenital heart disease, dysmorphic facial features and various degrees of intellectual disability. This is caused by germline mutations in genes encoding components or regulators of RAS / MAPK (mitogen activated protein kinase) signaling pathway that lead to dysregulation of cell signal transmission. The diseases of the RASopathies group include neurofibromatosis type 1, Noonan syndrome, Noonan syndrome with multiple lentigines, Leopard syndrome, hereditary gingival fibromatosis type 1, capillary malformation-arteriove- nous malformation syndrome, Costello syndrome, cardio-facio-cutaneous syndrome, and Legius syndrome [9].

Neurofibromatosis type 1 (NF1) is a syndrome in group of RASopathies is one of the most common Mendelian diseases. It was first described in 1882 by Friedrich Danie Von Recklinghausen as a case report. Therefore, the other name of the disease is Von Recklinghausen disease. The incidence of disease is approximately 1 in 2600 to 3000 individuals [10]. The disease is inherited as autosomal dominant. Half of the affected individuals $(50 \%)$ had a de novo mutation in NF1 gene. NF1 syndrome is caused by mutations in the NF1 gene [11]. Genetic variants caused for the disease are mostly mutations that cause truncated protein production (complete gene deletions, insertions, stop, and splicing mutations) [12]. NF1 clinical symptoms and signs are caf'e-au-lait maculae, skin fold freckling, neurofibromas and plexiform neurofibromas, iris Lisch nodules, scoliosis, dysplasia of the long bone or sphenoid, optic pathway glioma, cardiac malformations, cardiovascular disease, vasculopathy, hypertension, and seizures. This syndrome also causes dysmorphic craniofacial features, mild intellectual disability, and a predisposition to developing some malignancies. Dysmorphic facial features are telecanthus, down-slanting palpebral fissures, eversion lower lateral eyelid fissures, large nose, high broad nasal bridge, thick ears helices, small and pointed chin. Diagnosis is provided with the presence of 2 of the disease suggestion criteria's. Suggestion criterias are (1) cafe'-au-lait spots (six or more and $>5 \mathrm{~mm}$ in greatest diameter in prepubertal individuals and $>15 \mathrm{~mm}$ in greatest diameter in postpubertal), (2) skin freckling (axillary or inguinal regions), (3) Lisch nodules (Two or more), (4) neurofibromas (two or more any type or one plexiform), (5) optic gliomas, (6) distinctive bony lesions, and (7) a first-degree family relative with NF1 [13]. Genetic diagnosis of NF1 is made by sequence analysis and gene-targeted deletion / duplication analysis in NF1 gene [14].

The aim of this study was to evaluate the clinical presentation of NF1 syndrome which is the one of common Mendelian disease and to present it to the literature. At the same time, another aim of this study is to evaluate and compare with other RASopathies diseases the success of Face2Gene application which is one of the NGP technologies, in this group of diseases. 


\section{METHODS}

This study was planned as a retrospective study. The files of the patients who applied to Medical Genetics Department of Afyonkarahisar Health Science University between 2012 and 2020 were re-reviewed. Patients included in the study were divided into 3 groups. Group 1 consist with patients have pre-diagnose as NF1 disease and detected mutation in the NF1 gene by molecular genetic analysis. The patients included in Group 2 have clinically diagnosed as RASopathies except NF1. Group 3 patients have Down syndrome. Inclusion and exclusion criterias for patients were determined as in Table 1. Consent was ob- tained from all patients.

Selected 14 patients for all 3 groups (Total count 42). The photos and relevant clinical features were uploaded to Face2Gene. In the suggestion list presented by the application, the presence of NF1 and non-NF1 RASopathy group diseases was annotated for Group 1 and Group 2. We also looked how the correct diagnosis is ranked by both types of analysis, DeepGestalt and Feature match. In addition, the RESEARCH application of Face2Gene was used to understand whether the tool can recognize the group of patients from control groups [15]. In a series of filtrations, we compared our test group to 2 different control groups - a cohort comprised of frontal facial photos of Down

Table 1. Inclusion and exclusion criterias for study

\section{Group 1}

Inclusion Criterias

-Patient consulted to the Afyonkarahisar Health Science University, Medical Genetics Department between 2012-2019

-Patients that have symptoms and signs for NF1 disease.

-Patients that have mutation in NF1 gene that detected by molecular genetics analysis.

-In patient files, having at least one frontal facial picture for analyzing in Face2Gene application

\section{Inclusion Criterias}

-Patient consulted to the Afyonkarahisar Health Science University, Medical Genetics Department between 2012-2019

-Patients were clinically diagnosed as one of RASopathies diseases except NF1 (non-NF1 RASopathies)

-In patient files, having at least one frontal facial picture for analyzing in Face2Gene application

\section{Exclusion Criterias}

-Patient has not consulted to the Afyonkarahisar Health Science University, Medical Genetics Department

-Patients that do not have symptoms and signs for NF1 diseases

-Patients do not have mutation in NF1 gene that detected by molecular genetics analysis or have not any genetics results.

-Patient does not have enough pictures for analyzing in Face2Gene application

\section{Group 2}

\section{Exclusion Criterias}

-Patient that were not consulted to Afyonkarahisar Health Science University, Medical Genetics Department
-Patients that do not have enough pictures for analyzing in Face2Gene application

\section{Group 3}

\section{Inclusion Criterias}

-Patients that were consulted to the Afyonkarahisar Health Science University, Medical Genetics

Department between 2012-2019

-Patients that received diagnosis based on G-banding karyotyping result as Down Syndrome.

-In patient files, having at least one frontal facial picture for analyzing in Face2Gene application

\section{Exclusion Criterias}

-Patients that were consulted to the Afyonkarahisar Health Science University, Medical Genetics Department

-Patients that did not receive diagnosis based on Gbanding karyotyping result as Down Syndrome.

-Patients that do not have enough pictures for analyzing in Face2Gene application 
syndrome patients (Group 3) and a cohort comprised of photos of unaffected cohort, of the same sex and age distribution.

In the NF1 disease the distinctive findings which are cafe'-au-lait spots, Lisch nodules, neurofibromas, optic gliomas, bony lesions and family history are reevaluated for Group 1 patients. For this reason, presenting symptoms, pedigree and MRI findings of patients were reached from hospital records. In addition, from the photos of Group 1 patients, the dysmorphic facial features were detected. In this process, The Elements of Morphology: Human Malformation Terminology was used [16].

The aim of this study is to evaluate the power of DeepGestalt algorithm that is one of the NGPs, to estimate NF1. We studied that this application could guide for medical geneticists in this group of diseases. We also aimed to present the clinical findings of patients with definite diagnosis NF1 to the literature.

This study approved by Afyonkarahisar Health Sciences University Ethic committee.

\section{Statistical Analysis}

Collected data were analyzed by Statistical Package for Social Sciences version 18.0 (SPSS Inc., SPSS IBM, Armonk, NY, USA). Continuous data were expressed as mean \pm standard deviation (range: minimum-maximum) whereas categorical data were denoted as numbers or percentages where appropriate. Chi-square test was used for the statistical comparisons. Two-tailed $p$ values less than 0.05 were accepted to be statistically significant.

\section{RESULTS}

The in forms of mutation in the NF1 gene and pedigrees of patients are presented in Table 2. In this study, $2(14.2 \%)$ of 14 patients are female. According from pedigree analysis of patients, only one patient (Case 12) has de novo mutation. Other 13 patients have another affected family member in their family. In this cohort the rate of de novo mutation is $7.14 \%$. Case 5 - 6 are uncle and nephew, Case 10 - 11 are siblings and Case 12 - 13 are mother and son. Two patients have intronic mutation, one of these is non-coding mutation (Case 3 ) and the other is splicing mutation (Case 7). Other 12 patients have mutation in

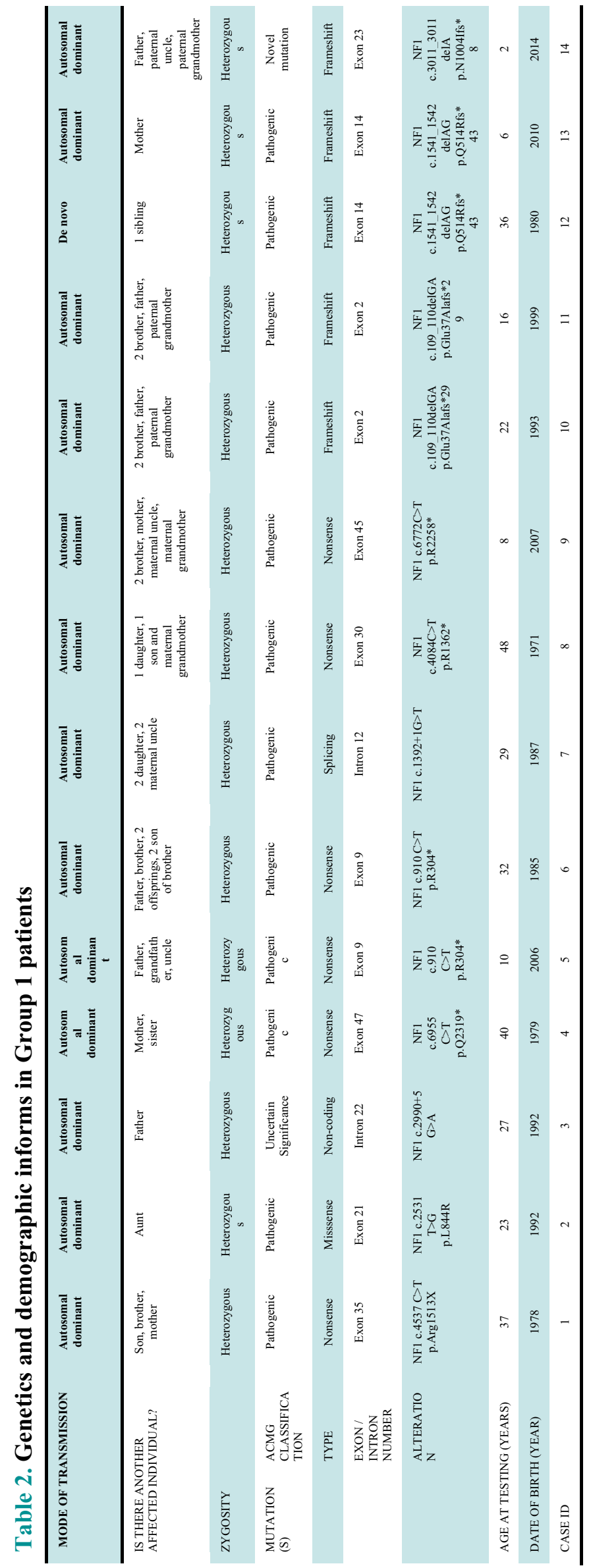


Table 3. Clinical, dysmorphic and radiological findings of Group1 patients

\begin{tabular}{ccc}
\hline CASE & PRESENTING & DYSMORPHIC FEATURES \\
ID & SYMPTOMS & \\
\hline
\end{tabular}

MRI FINDINGS

Multiple cafe au lait spots, neurofibromas, lisch nodules

$2 \quad$ Multiple cafe au lait spots, neurofibromas, unilateral hearing loss

3 Multiple cafe au lait spots

$4 \quad$ Multiple cafe au lait spots, neurofibromas

$5 \quad$ Multiple cafe au lait spots, seizure, neurdevelopmental delay, lisch nodules

6 Multiple cafe au lait spots, neurofibromas

$7 \quad$ Multiple cafe au lait spots, neurofibromas

$8 \quad$ Multiple cafe au lait spots, neurofibromas, sarcoma excision from arm

$9 \quad$ Multiple cafe au lait spots, ataxic gait

10 Multiple cafe au lait spots, neurofibromas

11 Multiple cafe au lait spots, neurofibromas

12 Multiple cafe au lait spots

13 Multiple cafe au lait spots, short stature

$14 \quad$ Multiple cafe au lait spots, developmental delay
Prominent supraorbital ridges, cheekbones prominence, deeply set eyes, prominent antihelix stems, protruding ears, macrotia, low insertion columella

Long face, broad forehead, deeply set eyes, broad eyebrows, thick eyebrows, long palpebral fissures, prominent antitragus, long ears, narrow nasal bridge, fullness paranasal tissue, deep philtrum, exaggerated Cupid's Bow

Long face, cheekbones prominence, broad chin, deeply set eyes, narrow nasal ridge, deep philtrum, exaggerated Cupid's Bow, thin lower lip vermilion

Long face, malar flattening, prominent nasolabial fold, broad chin, deeply set eyes, thick eyebrows,

telecanthus, enlarged nares, wide nasal base, wide nasal bridge, deep philtrum, exaggerated Cupid's Bow, thin lower lip vermilion

Malar flattening, thick eyebrows, telecanthus, thick ala nasis, bulbose nose, long philtrum, thick lower lip vermilion, thick upper lip vermilion

Long face, narrow face, prominence cheekbone, tall chin, thick eyebrows, low hanging columella, wide nasal base, thick upper lip vermilion, thick lower lip vermilion

Brachycephaly, frontal balding, long face, prominence cheekbones, long chin, deeply set eyes, hypotelorism, sparse eyebrow, prominent antitragus, thick ala nasi, low insertion columella, narrow nasal bridge, smooth philtrum

Long face, cheekbones prominence, malar flattening, broad chin, tall chin, deeply set eyes, downslanted palpebral fissures, high insertion columella, malaligned philtral ridges

Malar prominence, deeply set eyes, sparse eyebrows, infraorbital creases, upslanted palpebral fissures, ptosis, thick ala nasi, wide nasal bridge, wide nasal ridge, deep philtrum, exaggerated Cupid's Bow

Full cheeks, midface prominence, tall chin, downslanted palpebral fissures, wide nasal base, thick lower vermilion

Triangular face, full cheeks, midface prominence, pointed chin, downslanted palpebral fissures, wide nasal base, thick lower vermilion

Broad chin, tall chin, smooth philtrum, thin lower lip vermilion

Midface prominence, pointed chin, tall chin, wide spaced eyes, upslanted palpebral fissures, telecanthus, overfolded helix, narrow nasal ridge, exaggerated Cupid's Bow

Broad forehead, short chin, prominent antihelix stem, serpenginous antihelix stem, wide nasal base, wide mouth
Nonspecific hyperintense signal in

T2-FLAIR A sequences which is oval configuration measured as $7 \times 5$ $\mathrm{mm}$ in the right frontal white matter at the centrum semiovale level, L2-

S1 vertebra perineural cyst

Pontocerebellar arachnoid cyst, mega cisterna magna, right cerebellar hamartoma

\section{N/A}

Normal

Arachnoid cysts, cavum septum pellucidum et vergae

\section{N/A}

\section{Cerebellar hamartoma, neurofibromas}

Triceps muscle sarcoma, bladder mesenchymal sarcoma

Hamartomas in superficial and deep white matter, periventricular white matter, left cerebellar hemisphere, corpus callosum, bilateral globus pallidus Normal

N/A

Normal

Hamartomas in brain stem, cerebellar hemisphere and cerebral hemispheres, thickening of optic nerve

Normal 
exon. The most detected mutation is nonsense that has 6 patients. Five mutations are occurred as frameshift. One of these is a novel mutation (Case 14). In this study, there is only one missense mutation. Twelve patients of 14 have pathogenic mutations which are according to American College of Medical Genetics (ACMG) classification of mutations. One patient has "uncertain significance" variant. The range of age that patient have definitive diagnosis is between 2-48.

All of NF1 patients have consulted cause of multiple cafe au lait spots. Other presenting symptoms are neurofibromas, lisch nodules, neurodevelopmental delay, unilateral hearing loss, ataxic gait, short stature, seizure respectively. The most seen dysmorphic facial feature is both long face and deeply set eyes (42.8\%). The second is both exaggerated Cupid's Bow and tall chin $(35.7 \%)$ and the third is thick eyebrows (28.5\%). 3 patients didn't have any MRI. Four of 14 patients have hamartomas or hamartoma like image at brain MRI. Also 4 patients had "Normal" MRI. The patient who had pontocerebellar arachnoid cyst (Case 2) that's maybe why he had unilateral hearing loss and he was the only patient who have missense mutation in this study. At the same time Case 2, Case 7 and Case 13 had cerebellar hamartoma but he didn't have any cerebellar sign. Only one patient (Case 13) had thickening of optic nerve. The patient who had novel mutation in NF1 gene had developmental delay but he had normal MRI. All these informs are in Table 3.

The frontal facial photographs of each 14 NF1, Down syndrome and non-NF1 RASopathy patients were uploaded to Face2Gene application. The composite photos of each group are shown in picture 1 . The application also provides binary comparisons. According to application, the success of NF1 and 2 other disease groups (Down syndrome and non-NF1 RASopathies) of diagnosis was compared. In addition, 14 unaffected control cases were compared with NF1 patients. According to the binary comparison between NF1 and Down syndrome patients, area under the curve (AUC) value was calculated as 0.965 and $p$ value 0.007 . At the comparison of NF1 patients and non-NF1 RASopathies patients resulted as AUC was 0.749 and $p$ value was 0.134 . Also, at the comparison of 14 unaffected control cases and NF1 patients, AUC was calculated as 0.932 and $p$ value as 0.032 . When compared with Down syndrome and unaffected controls, AUC was 0.989 and $p$ value was 0.000 . In com- parison of NF1 patients and 3 other groups, AUC resulted as 0.855 and $p$ value as 0.034 . The Receiver operating characteristic (ROC) curve of these calculations is shown in picture 2 .

At the final of analysis Face2Gene application provides a list which 30 possible diseases for diagnosis. This list is presented depend on Gestalt Score and Feature Score. Accordingly, Gestalt Score is a number obtained according to the analysis of patients' photographs. Feature Score is the other number obtained by entering the clinical findings of the patients. Combined Score is calculated according to these two scores. For 14 patients with NF1, rank of NF1 disease at suggested syndromes list by the application, Gestalt score, Feature score and combined score are presented in Table 4. In addition, these scores and the rank for non-NF1 RASopathies diseases in the suggestion list which recommended by the application for these 14 patients are presented in Table 4. The application suggested this disease in top-3 for 10 of 14 NF1 patients. For 5 patients, non-NF1 RASopathies diseases were suggested at higher rankings than NF1 disease.

\section{DISCUSSION}

In this study, we presented genotype and phenotype findings of NF1 patients. According to aim of the study, success of new approach for phenotyping like DeepGestalt (Face2Gene application) technology evaluated. This new generation genetics disease diagnosis techniques may use in routinely at clinical practice for medical genetics doctors.

For autosomal dominant disorders, de novo mutations which is mean an alteration in a gene that is present for the first time in one family member, have high rate [17]. NF1 is one of in this group disease. Almost half of NF1 disease occurs as de novo [18]. In this study, we could not do segregation analysis. But according to pedigree analysis de novo mutation rate found as $7.14 \%$. Possible cause of this condition may be the fitness of NF1 disease is high.

The mutation type is one of elements that are benefited for classification of mutation. That's why, when genotyping, mutation type is one of important stage. Mutation type rates in NF1 gene are reported as for nonsense mutation is between $21 \%-38 \%$ [19, 20]. According to ClinVar genetic database, 407 of 6254 vari- 
ants are reported as nonsense. In this study, nonsense mutations rate was $42.8 \%$. Additionally, second most detected mutation type in this study is frameshift mutation $(35.7 \%)$. In the literature, frameshift mutation rate is reported between $47 \%-26 \%[19,21]$. The missense mutation rate in the NF1 gene has been reported as between 60 and $12 \%[19,22,23]$. In our study, the rate of this mutation type is lowest one (7\%). The rate of mutations occurring in the intronic region of the NF1 gene, which constitute regions of gene that are not translated to protein, has been reported to be 43$20 \%[21,23]$. In this study, the intronic mutation rate was found as $14 \%$. Considering that variants that cause NF1 disease may occur not only in exons but

\section{Table 4. Face2Gene analysis results of patients with NF1}

\begin{tabular}{|c|c|c|c|c|c|c|c|c|c|c|}
\hline \multirow[b]{2}{*}{$\underset{0}{0}$} & \multicolumn{5}{|c|}{ NF1 Scores } & \multicolumn{5}{|c|}{ NON-NF1 RASopathy Scores } \\
\hline & 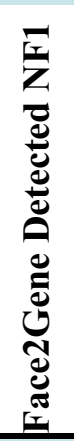 & 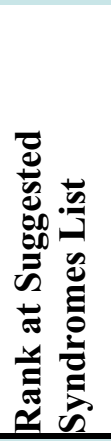 & 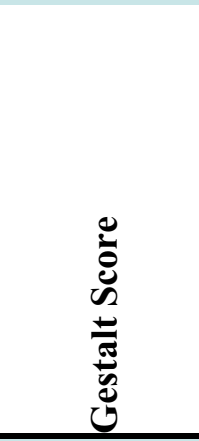 & 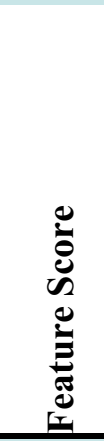 & 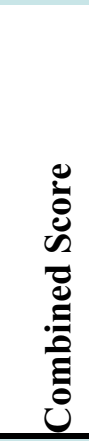 & 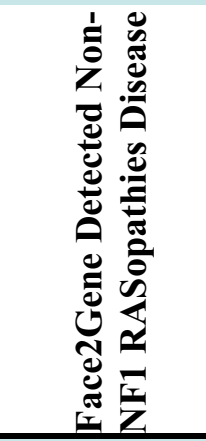 & 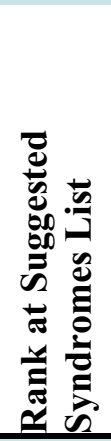 & 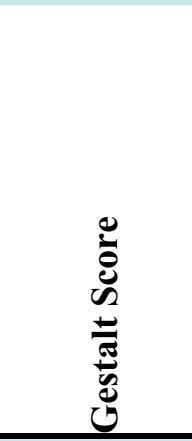 & 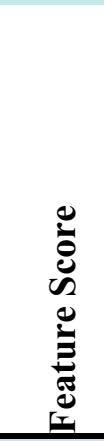 & 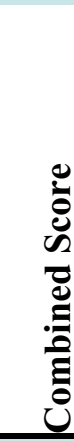 \\
\hline P1 & + & 1 & 0.140658 & 1 & 0.58 & $\begin{array}{l}\text { Noonan } \\
\text { Syndrome }\end{array}$ & 3 & 0.17825 & 0.5 & 0.26 \\
\hline $\mathrm{P} 2$ & + & 1 & 0.24933 & 0.56 & 0.56 & $\begin{array}{l}\text { LEOPARD } \\
\text { Syndrome }\end{array}$ & 2 & 0.171426 & 0.73 & 0.33 \\
\hline P3 & + & 3 & 0.200005 & 0.84 & 0.29 & $\begin{array}{l}\text { LEOPARD } \\
\text { Syndrome }\end{array}$ & 8 & 0.0931721 & 1 & 0.11 \\
\hline P4 & + & 2 & 0.246332 & 0.75 & 0.33 & $\begin{array}{l}\text { Noonan } \\
\text { Syndrome }\end{array}$ & 1 & 0.26077 & 0.45 & 0.51 \\
\hline P5 & + & 2 & 0.095214 & 1 & 0.3 & $\begin{array}{l}\text { Noonan } \\
\text { Syndrome }\end{array}$ & 1 & 0.139438 & 0.5 & 0.51 \\
\hline P6 & + & 3 & 0.184519 & 0.75 & 0.21 & $\begin{array}{l}\text { Legius } \\
\text { Syndrome }\end{array}$ & 5 & 0 & 0.87 & 0.17 \\
\hline P7 & + & 1 & 0.690764 & 0.99 & 0.57 & $\begin{array}{l}\text { LEOPARD } \\
\text { Syndrome }\end{array}$ & 3 & 0.355832 & 1 & 0.21 \\
\hline P8 & + & 1 & 0.272886 & 0.8 & 0.58 & $\begin{array}{l}\text { Noonan } \\
\text { Syndrome }\end{array}$ & 3 & 0.236196 & 0.55 & 0.18 \\
\hline P9 & + & 6 & 0.107819 & 0.55 & 0.14 & $\begin{array}{l}\text { LEOPARD } \\
\text { Syndrome }\end{array}$ & 7 & 0.050874 & 0.92 & 0.13 \\
\hline P10 & + & 4 & 0.169717 & 0.75 & 0.17 & $\begin{array}{l}\text { Noonan } \\
\text { Syndrome }\end{array}$ & 1 & 0.247422 & 0.45 & 0.51 \\
\hline P11 & + & 6 & 0.143984 & 0.75 & 0.15 & $\begin{array}{l}\text { Noonan } \\
\text { Syndrome }\end{array}$ & 1 & 0.209742 & 0.45 & 0.51 \\
\hline P12 & + & 1 & 0.0717643 & 1 & 0.6 & $\begin{array}{l}\text { LEOPARD } \\
\text { Syndrome }\end{array}$ & 4 & 0.0586419 & 1 & 0.22 \\
\hline P13 & + & 1 & 0.111643 & 0.51 & 0.55 & $\begin{array}{l}\text { LEOPARD } \\
\text { Syndrome }\end{array}$ & 4 & 0.0741118 & 0.78 & 0.2 \\
\hline P14 & + & 8 & 0.0683091 & 0.79 & 0.12 & $\begin{array}{l}\text { LEOPARD } \\
\text { Syndrome }\end{array}$ & 6 & 0.0490429 & 0.9 & 0.14 \\
\hline
\end{tabular}


also that may be occur in the intronic region, genetic analysis should be selected. For this reason, it is recommended to choose genetics analysis methods such as next generation sequencing which can detect changes in the intronic region.

Variants determined by genetic analysis are divided into 5 classes according to ACMG criteria. Class 2 is "Likely pathogenic" and Class 1 is reported as "Pathogenic". Variants in these two criteria groups are considered to be responsible for possible disease [24]. Until now, 96 Likely pathogenic and 1753 Pathogenic variants of the NF1 gene have been reported in the ClinVar database. Also, more than 2.800 different pathogenic variants in NF1 gene have been identified in the University of Alabama cohort [25]. In the literature, pathogenic mutation detection rate is between $89 \%$ and $96 \%[19,22,26]$. In this study, as a result of 14 NF1 analyzes, only 1 of them was "likely pathogenic" which is a novel mutation, while the other 13 analyzes resulted as a "pathogenic" variant (92\%). The detected novel mutation is NF1 c.3011_3011delA p.N1004Ifs*8. The detected mutation causes frameshift, creating an early stop codon and it is occurred in exon 23.

With the advances in technology, the success of medical doctors in diagnosing genetic diseases is increasing. DeepGestalt technology (Face2Gene), which uses artificial intelligence, is one of them. The success of this application in diagnosis has been reported to be $86-91 \%[7,8]$. All NF1 patients analysis results $(14 / 14$ $-100 \%$ ) are in the top-10 suggestion list recommended by the application. When compared to NF1 patients and unaffected controls at Face2Gene analysis, significant result was found ( $p=0.032)$. However, the success of the application in distinguishing between NF1 and non-NF1 RASopathies patients was not significant in this study ( $p=0.134)$. The reason for this may be that not enough RASopathies patients have been registered to the app. Therefore, next-generation phenotyping (NGP) programs such as Face2Gene are recommended to be used in routine examinations, especially by medical genetics doctors and pediatricians. In addition, there is an excellent separation when comparing the Down syndrome and the unaffected control group $(p<0.001)$. This shows that Face2Gene's success is high in patients with distinct dysmorphic facial features.

The brain is the control center of our whole body like the maestro. Perhaps for this reason, it is protected by a very tight and protected bone layer that is skull. Therefore, it was not easy to detect morphological changes in the brain until MRI was invented. Nowadays, we can almost take a picture of the brain with MRI. NF1 disease also causes some changes in the brain. In the study by Rosenbaum et al. [27], MRI was reported as normal in $6.5 \%$ of NF1 patients. In our study, this rate is $28 \%$. This is an example of NF1 patients can be in a wide spectrum. In genetics, this situation is described as variable expressivity and NF1 is one of the genetic diseases that have high variable expressivity [28]. In a study made in Spain in 2019, arachnoid cysts were detected in $3(3.5 \%)$ of $85 \mathrm{NF} 1$ patients in brain MRI [29]. In our study, arachnoid cysts were found in $3(\% 21)$ of 14 patients. In the study of Kelesoglu et al. [30], hamartomatous lesions in the central nervous system were reported in 16 of 19 patients (84\%) followed up with diagnosed with NF1 [30]. In our study, this rate was found as $29 \%$. As can be seen from these rates, it is not possible to diagnose NF1 only with MRI. There is no specific brain MR image for this disease. However, because of this disease causes various lesions in the brain, brain MRI may be recommended for all patients diagnosed with NF1.

\section{CONCLUSION}

One of the most important lessons we learned in our education at the medical school is that diagnosing diseases is one step ahead of treating. Because no disease can be cured without being diagnosed. In the past, diseases were evaluated generally, but with the advancement of technology, they can now be evaluated in more detail and individually. Eric Topol's following sentence expresses this situation well. Medicine is still all about treating populations, not people - one-sizefits all treatments and diagnosis. Therefore, "Next generation phenotyping" is gaining importance day by day and helps diagnose diseases.

\section{Authors' Contribution}

Study Conception: ME; Study Design: BG; Supervision: ME; Funding: BG; Materials: ME; Data Collection and/or Processing: BG; Statistical Analysis and/or Data Interpretation: ME; Literature Review: 
BG; Manuscript Preparation: ME and Critical Review: BG.

\section{Ethics Declarations}

All participants gave their informed consent and were studied under a protocol approved by the Health Sciences University Medical Ethics Committee.

\section{Data Availability Statement}

Data sharing is not applicable to this article as no new data were created in this study.

\section{Conflict of interest}

The authors disclosed no conflict of interest during the preparation or publication of this manuscript.

\section{Financing}

The authors disclosed that they did not receive any grant during conduction or writing of this study.

\section{Acknowledgements}

First of all, we thank the patients and their family. Then we thank to Nicole Fleischer for her help.

\section{REFERENCES}

1. Basel D. 25 - Dysmorphology. In: Kliegman RM, Lye PS, Bordini BJ, Toth H, Basel D, editors. Nelson Pediatr. SymptomBased Diagnosis. Elsevier; 2018. p. 393-410.e1.

2. Starbuck J. On the antiquity of trisomy 21: moving towards a quantitative diagnosis of Down syndrome in historic material culture. J Contemp Anthropol 2011;2:18-44.

3. Ruggieri M, Praticò AD, Caltabiano R, Polizzi A. Early history of the different forms of neurofibromatosis from ancient Egypt to the British Empire and beyond: first descriptions, medical curiosities, misconceptions, landmarks, and the persons behind the syndromes. Am J Med Genet A 2018;176:515-50.

4. Hart TC, Hart PS. Genetic studies of craniofacial anomalies: clinical implications and applications. Orthod Craniofac Res 2009;12:212-20.

5. Fischer C, Schweigert S, Spreckelsen C, Vogel F. Programs, databases, and expert systems for human geneticists--a survey. Hum Genet 1996;97:129-37.

6. Gurovich Y, Hanani Y, Bar O, Fleischer N, Gelbman D, Baselsalmon L, et al. DeepGestalt - identifying rare genetic syndromes using deep learning. arXiv 2017:1801-07637v1

7. Gurovich Y, Hanani Y, Bar O, Nadav G, Fleischer N, Gelbman $\mathrm{D}$, et al. Identifying facial phenotypes of genetic disorders using deep learning. Nat Med 2019;25:60-4.

8. Mishima H, Suzuki H, Doi M, Miyazaki M, Watanabe S. Evaluation of Face2Gene using facial images of patients with con- genital dysmorphic syndromes recruited in Japan. J Hum Genet 2019;64:789-94.

9. Tidyman WE, Rauen KA. Pathogenetics of the RASopathies. Hum Mol Genet 2016;25:R123-32.

10. Evans DG, Howard E, Giblin C, Clancy T, Spencer H, Huson $\mathrm{SM}$, et al. Birth incidence and prevalence of tumor-prone syndromes: estimates from a UK family genetic register service. Am J Med Genet 2010;152A:327-32.

11. Valero MC, Pascual-Castroviejo I, Velasco E, Moreno F, Hernández-Chico C. Identification of de novo deletions at the NF1 gene: no preferential paternal origin and phenotypic analysis of patients. Hum Genet 1997;99:720-6.

12. Boyd KP, Korf BR, Theos A. Neurofibromatosis type 1. J Am Acad Dermatol 2009;61:1-14.

13. Williams VC, Lucas J, Babcock MA, Gutmann DH, Bruce B, Maria BL. Neurofibromatosis type 1 revisited. Pediatrics 2009;123:124-33.

14. Valero MC, Martín Y, Hernández-Imaz E, Hernández AM, Meleán G, Valero AM, et al. A highly sensitive genetic protocol to detect NF1 mutations. J Mol Diagnostics 2011;13:113-22.

15. Pantel JT, Zhao M, Mensah MA, Hajjir N, Hsieh T-C, Hanani $\mathrm{Y}$, et al. Advances in computer-assisted syndrome recognition by the example of inborn errors of metabolism. J Inherit Metab Dis 2018;41:533-9.

16. Allanson JE, Biesecker LG, Carey JC, Hennekam R. Elements of morphology: introduction. Am J Med Genet A 2009;149A:2-5.

17. Retterer K, Juusola J, Cho MT, Vitazka P, Millan F, Gibellini F, et al. Clinical application of whole-exome sequencing across clinical indications. Genet Med 2016;18:696-704.

18. Robert L. Nussbaum MDFF, McInnes RR, Willard HF. Thompson \& Thompson Genetics in Medicine. Elsevier Health Sciences. 2015.

19. Zhang J, Tong H, Fu X, Zhang Y, Liu J, Cheng R, et al. Molecular characterization of NF1 and neurofibromatosis type 1 genotype-phenotype correlations in a Chinese population. Sci Rep 2015;5:1-5.

20. Thomson SAM, Fishbein L, Wallace MR. NFI mutations and molecular testing. J Child Neurol 2002;17:555-61.

21. Pros E, Gómez C, Martín T, Fábregas P, Serra E, Lázaro C. Nature and mRNA effect of 282 different NF1 point mutations: focus on splicing alterations. Hum Mutat 2008;29:E173-93.

22. Calì F, Chiavetta V, Ruggeri G, Piccione M, Selicorni A, Palazzo D, et al. Mutation spectrum of NF1 gene in Italian patients with neurofibromatosis type 1 using Ion Torrent PGMTM platform. Eur J Med Genet 2017;60:93-9.

23. Jeong SY, Park SJ, Kim HJ. The spectrum of NF1 mutations in Korean patients with neurofibromatosis type 1. J Korean Med Sci 2006;21:107-12.

24. Richards S, Aziz N, Bale S, Bick D, Das S, Gastier-Foster J, et al. Standards and guidelines for the interpretation of sequence variants: a joint consensus recommendation of the American College of Medical Genetics and Genomics and the Association for Molecular Pathology. Genet Med 2015;17:405-24.

25. Koczkowska M, Chen Y, Callens T, Gomes A, Sharp A, Johnson $\mathrm{S}$, et al. Genotype-phenotype correlation in NF1: evidence for a more severe phenotype associated with missense mutations 
affecting NF1 codons 844-848. Am J Hum Genet 2018;102:6987.

26. Evans DG, Bowers N, Burkitt-Wright E, Miles E, Garg S, Scott-Kitching V, et al. Comprehensive RNA analysis of the NF1 gene in classically affected NF1 affected individuals meeting $\mathrm{NIH}$ criteria has high sensitivity and mutation negative testing is reassuring in isolated cases with pigmentary features only. EBioMedicine 2016;7:212-20.

27. Rosenbaum T, Engelbrecht V, Krölls W, Van Dorsten FA, Hoehn-Berlage M, Lenard HG. MRI abnormalities in neurofibromatosis type 1 (NF1): a study of men and mice. Brain Dev 1999;21:268-73.
28. Sabbagh A, Pasmant E, Laurendeau I, Parfait B, Barbarot S, Guillot B, et al. Unravelling the genetic basis of variable clinical expression in neurofibromatosis 1. Hum Mol Genet 2009;18:2768-78.

29. Sánchez Marco SB, López Pisón J, Calvo Escribano C, González Viejo I, Miramar Gallart MD, Samper Villagrasa P. Neurological manifestations of neurofibromatosis type 1: our experience. Neurologia (Engl Ed) 2019;S0213-4853(19)30077-5. 30. Keleşoğlu KS, Keskin S, Sivri M, Erdoğan H, Nayman A, Koplay M. [Neurofibromatosis type 1: Cranial MRI findings]. Genel Tip Derg 2014;24:150-4. [Article in Turkish] 